the named participants in the Study Institute, soliciting comments from them on these views, but would welcome the opportunity of opening the debate up within a wider section of scientific opinion, through your columns. Can we invite those readers of Nature who have views on this matter to communicate directly with us?

Yours faithfully,
JIM COHEN
JOHN HAMBLEY
JAVAD HASHTEROUDIAN
JEFF HAYWOOD
LES PEARCE
KEN RICHARDSON
STEVEN ROSE
ARUN SINHA
DAVID SPEARS
BRIAN TIPLADY

Brain Research Group*,

Open University,

Walton,

Bletchley,

Buckinghamshire

*Correspondence to the Group.

\section{Predicting Population}

SIR,-There are two additional factors in the prediction of population besides those which were mentioned in John Maddox's article (Nature, 236, 267 ; 1972), which seem to me to be worth comment.

The first is that in educated and civilized communities, people's behaviour in reproductive as well as other respects is determined not only by their immediate and past environment as it is with most other creatures, but also with their expectations for the future. In consequence, coming events cast their shadow before on birth rates to an extent which is becoming increas. ingly important.

Arising out of this is the second factor which I would like to mention. This is rather like an extension of the uncertainty principle in physics. When Ehrlich, or Forrester and his computers, make convincingly unpleasant predictions concerning world population, these predictions will be read and understood by large numbers of people whose behaviour may thereby be affec- ted. Therefore even if the prophets have taken every possible existing factor into account, they cannot take into account the effects of their own predictions.

It is difficult to feed into a computer analysis the effects of knowledge of its own extrapolations on birth rates or pollution. It is, however, abundantly apparent that our responses to pollution and population changes are far more determined by their rates of change, and hence the direct extrapolations of their effect, than they are by the present magnitudes. Forrester explicitly rules this out in his computer calculations, and thereby, it seems to me, very reliably invalidates them.

This is not a criticism of the value of predictions; rather it is an explanation of where their value lies. A prediction which could not be modified by a change in our actions really would be useless. Yours faithfully,

J. H. FREMLIN

Department of Physics,

University of Birmingham,

PO Box 363,

Birmingham B15 2TT

\title{
Obituary
}

\section{Professor N. P. Buu-Hoï}

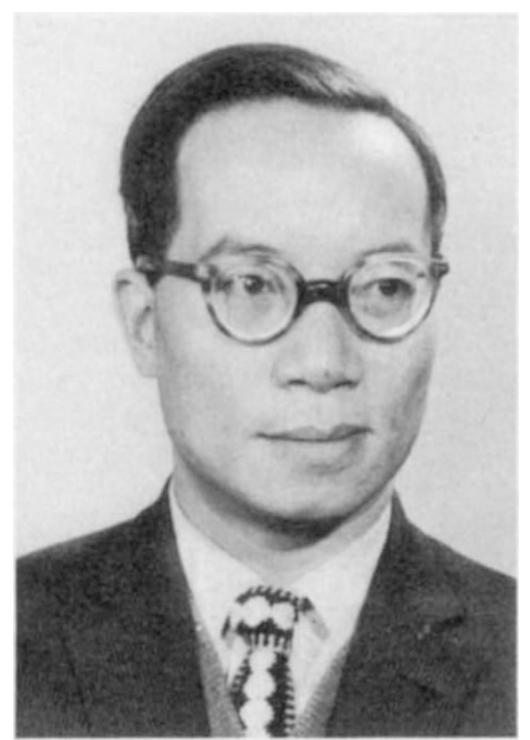

Professor BuU-Hoï, French and Vietnamese expert in medicinal chemistry and cancer research, died of a heart attack in Paris on January 28, 1972.

N. P. Buu-Hoï was born on June 15 , 1915 , in Hué, and is of the Royal Family of Vietnam. Partly because of the desire of his parents and partly because of his own belief in the human value of science, he did not follow the traditional political career of his family, but instead took up research in biochemistry and medicine. He studied pharmacology at the University of Hanoi, and upon arrival in France in 1935 took degrees in physics and chemistry at the University of Paris. During the Second World War he volunteered as a pharmacist in the medical service of the French Army. From 1941 he held appointments on the research staff of the Centre National de la Recherche Scientifique (CNRS) where in 1960 he became director of research.

After 1941, he worked at the Institute of Chemical Physics under the late Professor Jean Perrin, then studied spectroscopy applied to organic chemistry, under the late Professor Ramart-Lucas at the Sorbonne. From 1945 to 1947 he was assistant professor at the Ecole Polytechnique, and then went to the Radium Institute of the University of Paris as director of the Department of Organic and Medicinal Chemistry, where for more than twenty years he was the closest collaborator of the renowned cancerologist Professor Antoine Lacassagne, who himself died recently (see Nature, 235, $291 ;$ 1972). In 1960 he transferred his laboratories to a laboratory group at Gif-sur-Yvette, where he led a team of some 20 researchers while continuing his collaboration with Professor Lacassagne at the Radium Institute. From 1967, he also directed a second team of researchers at the CNRS Laboratories in Orleans.

The main research interests of BuuHoi were in the fields of biochemistry and pharmacolugy, but his exceptional gift as an organic chemist enabled him to apply the whole panorama of possibilities of synthetic chemistry to the search for new compounds of biochemical, biological, and pharmacological activity.

His scientific bibliography comprises over 1,000 papers and chapters in books, and records fundamental knowledge in chemistry, pharmacology and cancer research. From his laboratory stem drugs now in clinical practice as well as in experimental development, such as new thiourea derivatives for tuberculosis and leprosy, thyronamine for cardiac conditions, 6-aminochrysene for splenomegaly and cancer chemotherapy, and anti-rheumatismal agents and analgesics.

The study of chemical carcinogenesis represents the core of his scientific acti- 